\title{
KAJIAN REKLAMASI LAHAN DAERAH ALIRAN SUNGAI BATANG KURANJI KOTA PADANG
}

\author{
Ade Irma Suryani \\ Progam Studi Pendidikan Geografi STKIP PGRI Sumatera Barat \\ Email: adeirmasuryani610@yahoo.com
}

\begin{abstract}
Reclamation activities aimed at fixing or setting up a land use that is disturbed as a result of business activities penggolahan inappropriate environment, in order to function and useful for their designated purpose. This study aims to determine land use (DAS) Kuranji Batang Padang city, and the direction of land reclamation in the watershed (DAS) Kuranji Batang Padang. Tutorial reklamsi done on land along the streams of the river is, with methods of soil conservation by means of agronomic or vegetative, mechanical and chemical.

Keywords: watershed, land use, land reclamation landing
\end{abstract}

\begin{abstract}
Abstrak
Reklamasi adalah kegiatan yang bertujuan memperbaiki atau menata kegunaan lahan yang terganggu sebagai akibat kegiatan usaha penggolahan lingkungan yang tidak tepat, agar dapat berfungsi dan berdaya guna sesuai peruntukannya. Penelitian ini bertujuan untuk mengetahui penggunaan lahan pada (DAS) Batang Kuranji Kota Padang, dan arahan reklamasi lahan di daerah aliran sungai (DAS) Batang Kuranji Kota Padang. Arahan reklamsi lahan dilakukan pada sepanjang daerah airan sungai Yaitu dengan metode konservasi tanah dengan cara agronomis atau vegetatif, mekanik dan kimia.

Kata kunci: DAS, pengunaan lahan, arahan reklamasi lahan
\end{abstract}

\section{PENDAHULUAN}

Reklamasi adalah kegiatan yang bertujuan memperbaiki atau menata kegunaan lahan yang terganggu sebagai akibat kegiatan usaha penggolahan lingkungan yang tidak tepat, agar dapat berfungsi dan berdaya guna sesuai peruntukannya. Pembangunan berwawasan lingkungan menjadi suatu kebutuhan penting bagi setiap bangsa dan Negara yang menginginkan kelestarian sumberdaya alam. Oleh sebab itu, sumberdaya alam peru di jaga dan dipertahankan untuk kelangsungan hidup manusia kini, maupun untuk generasi yang akan datang (Arif, 2007 dalam Suprato).

Daerah Aliran Sungai (DAS) mempunyai karakteristik yang spesifik serta berkaitan erat dengan unsur utamanya seperti jenis tanah, tataguna lahan, 
topografi, kemiringan dan panjang lereng. Diantara faktor-faktor yang berperan dalam menentukan system hidrologi tersebut, faktor tataguna lahan, kemiringan dan panjang lereng dapat direkayasa oleh manusia Asdak (2002). Peranan vegetasi sangat penting artinya karena kemungkinan intervensi manusia terhadap unsur tersebut amat besar. Kebutuhan akan lahan semakin meningkat sementara jumlah lahan khususnya lahan hutan tidak bertambah luas malah cenderung berkurang. Luas lahan hutan yang harus dipertahankan dalam suatu kesatuan Daerah Aliran Sungai (DAS) agar dapat menjamin kelestarian sumber air. Masalah ini cukup kompleks mengingat berbagai kepentingan atas tataguna lahan di DAS antar berbagai sektor serta untuk memenuhi kebutuhan masyarakat. Fungsi ekologis hutan sangat penting utamanya untuk menjaga erosi serta mengatur tata air khususnya di sungaisungai. Menurut Undang-undang Pokok Kehutanan No. 41 tahun 1999 "Luas hutan yang perlu dipertahankan minimal 30\% dari luas daratan”. Untuk menjaga fungsi ekologi, ekonomi dan sosial budaya, keberadaan hutan mutlak dipertahankan pada suatu daerah aliran sungai (DAS) ( Suryani, 2014).

Batang Kuranji merupakan sungai yang membelah kota Padang di Provinsi Sumatera Barat. Sungai ini berhulu pada sekitar Bukit Barisan antara Kabupaten Solok dengan Kota Padang, dan bermuara di Samudera Hindia. Tingginya aktifitas masyarakat dalam penggunaan lahan daerah aliran sungai mengakibatkan terexpoetasinya lahan-lahan disekitar DAS yang mengakibatkan menurunnya kwalitas tanah dan menyebabkan terjadinya degradasi tanah di sepanjang Aliran Sungai maka oeh sebab itu daerah sepanjang aliran sungai memerlukan rakamasi lahan agar keseimbangan alam di sekitar DAS tersebut tetap terjaga. Sesuai dengan latar belakang masalah tersebut maka penelitian ini berjudul "Kajian Reklamasi Lahan Derah Aliran Sungai Batang Kuranji Kota Padang" 


\section{METODE PENELITIAN}

Penelitian yang dilakukan termasuk jenis penelitian analisis deskriptif dengan pendekatan kuantitatif. membuat gambaran secara sistematis faktual dan akurat mengenai faktor-faktor serta hubungan yang akan diteliti dan menggunakan pendekatan keruangan dan pendekatan ekologi.

\section{PEMBAHASAN}

Daerah Aliran Sungai Batang Kuranji secara geografis terletak pada $00^{\circ} 48^{\prime}-00^{0} 56^{\prime}$ LU dan $100^{\circ} 20^{\prime}-100^{0} 34^{\prime}$ BT. Welayah yang tercakup DAS Batang Kuranji dari hulunya dibatas kota Padang dengan Kabupaten Solok sampai garis pantai barat Sumatera, yang mencakup lima kecamatan yaitu : Kecamatan Pauh, Kuranji, Nanggalo, Padang Utara Dan Kota Tangah dengan ketinggian dari permukaan laut $1.858 \mathrm{~m}$ dpl $94.9 \mathrm{~m}$ dpl dan luas $22.251 \mathrm{Ha}$

\section{Penggunaan lahan}

Penggunaan lahan merupakan hasil akhir dari setiap bentuk campur tangan kegiatan manusia terhadap lahan di permukaan bumi yang bersifat dinamis dan berfungsi untuk memenuhi kebutuhan hidup baik material maupun spiritual Arsyad dalam suarna (2010). Perubahan pengunaan lahan adalah bertambahnya suatu penggunaan lahan dari suatu sisi penggunaan ke penggunaan yang lainnya diikuti dengan berkurangnya tipe penggunaan lahan yang lain dari suatu waktu ke waktu berikutnya, atau berubahnya fungsi suatu lahan pada kurun waktu yang berbeda Wahyunto,dkk dalam (Suarna, 2010 dalam Suryani, 2014).

Peningkatan jumlah dan kepadatan penduduk di suatu wilayah juga akan mengakibatkan meningkatnya jumlah penduduk yang kebanyakan menggantungkan hidupnya pada aktivitas pertanian. Peningkatan ini secara langsung menyebabkan beberapa masalah lingkungan, dimana kebutuhan 
akan lahan pertanian dan juga permukiman pada umumnya dikompensasi dengan penyusutan lahan hutan dan vegetasi alami/semi alami lainnya.

Dengan demikian, terjadilah proses perubahan penutup dan penggunaan lahan sekaligus. Perubahan semacam ini membawa efek negatif pada proses-proses hidrologi di suatu Daerah Aliran Sungai (DAS). Perubahan penutup vegetasi di DAS dapat dihipotesiskan mengakibatkan dampak negatif terhadap penurunan kwalitas tanah dan pada akhirnya juga menimbulkan penurunan kwalitas tanah maka harus adanya kegiatan reklamasi

\section{Arahan Reklamasi Lahan}

Luntungan (1998;12) menjelaskan bahwa arahan fungsi pemanfaatan lahan merupakan kajian potensi lahan untuk peruntukan suatu kegiatan kedalam suatu kawasan tertentu berdasarkan fungsi utamanya. Arahan fungsi pemanfaatan lahan juga dapat diartikan sebagai upaya untuk menata pemanfaatan lahan pada suatu kawasan sesuai dengan kemampuannya Dalam hal ini tujuan dari arahan fungsi pemanfaatan lahan adalah untuk mencapai keseimbangan antara kemampuan lahan dengan jenis pemanfaatan dan teknologi yang digunakan sebagai upaya untuk melindungi kelangsungan fungsi dan manfaat sumberdaya alam di suatu DAS. Artinya apabila penggunaan lahan pada masing-masing kawasan tidak sesuai dengan fungsi utamanya maka perlu dilakukan tindakan arahan fungsi pemanfaatan lahan dengan menerapkan tindakan rehabilitasi lahan dan konservasi tanah secara vegetatif dan mekanik yang bertujuan untuk mengembalikan dan menjaga fungsi utama kawasannya.

Utomo (1994: 66) memberikan definisi konservasi dan rehabilitasi tanah sebagai berikut: Konservasi tanah adalah menggunakan tanah sesuai dengan daya guna dan kemampuan kemudian jika kita sudah memanfaatkannya kita harus memelihara/mempertahankan produktifitasnya 
dengan jalan memperlakukan dengan syarat yang diperlukan. Dan jika menghadapi tanah yang telah telanjur rusak, kita bertugas untuk memperbaiki produktifitasnya. Kegiatan yang terakhir ini juga dikenal dengan istilah "reklamasi tanah" atau rehabilitasi tanah.

Konservasi tanah tidak berarti penundaan pemanfaatan tanah, tetapi menyesuaikan macam penggunaannya dengan sifat-sifat atau kemampuan tanah dan memberikan perlakuan dengan syarat-syarat yang diperlukan. Secara garis besar metode konservasi tanah dapat dikelompokkan menjadi tiga golongan utama, yaitu : (1) secara agronomis atau vegetatif, (2) secara mekanik dan (3) secara kimia. (Suripin, 2004 : 101). Konservasi tanah secara vegetatif adalah penggunaan tanaman atau tumbuhan dan sisa tanaman dengan cara sedemikian rupa sehingga dapat mengurangi laju erosi dengan cara mengurangi daya rusak hujan yang jatuh dan jumlah daya rusak aliran permukaan. Konservasi tanah secara mekanik adalah konsevasi yang berkonsentrasi pada penyiapan tanah supaya dapat ditumbuhi vegetasi yang lebat, dan cara mamanipulasi topografi mikro untuk mengendalikan aliran air dan angin. (Suripin, 2004: 101).

Arahan fungsi pemanfaatan lahan merupakan bagian dari Pola Rehabilitasi Lahan dan Konservasi Tanah yang biasanya menggunakan Daerah Aliran Sungai (DAS) sebagai unit perencanaan sekaligus sebagai unit wilayah kerja kegiatan rehabilitasi lahan dan konservasi tanah.

\section{Beberapa bentuk kegiatan Reklamasi atau rehabilitasi lahan dan konservasi tanah tersebut dapat dijelaskan sebagai berikut :}

A. Reboisasi dapat diartikan sebagai usaha untuk memulihkan dan menghutankan kembali tanah yang mengalami kerusakan fisik, kimia maupun biologi baik secara alami maupun oleh ulah manusia. Reboisasi merupakan cara yang cocok untuk menurunkan erosi aliran permukaan, terutama jika dilakukan pada bagian hulu daerah tangkapan air untuk 
mengatur banjir. Tanaman yang digunakan biasanya tanaman yang bisa mencegah erosi, baik secara habitus maupun umur, juga diutamakan tanaman keras yang bernilai ekonomis, baik kayunya maupun hasil samping lainnya, misalnya getah, akar dan minyak. Dalam kaitannya dengan usaha konservasi, tanaman yang dipilih hendaknya mempunyai persyaratan sebagai berikut:

1. Mempunyai sistem perakaran yang kuat, dalam dan luas, sehingga membentuk jaringan akar rapat.

2. Pertumbuhannya cepat, sehingga mampu menutup tanah dalam waktu singkat.

3. Mempunyai nilai ekonomis, baik kayunya maupun hasil sampingnya.

Dapat memperbaiki kualitas/kesuburan tanah. (Suripin, 2004: 113114)

B. Perlindungan sungai yaitu penanaman tanaman secara tetap berbentuk jalur hijau di sepanjang tepi kanan kiri sungai dengan memilih jenis tanaman yang memenuhi syarat untuk tujuan perlindungan, yaitu tanaman yang mempunyai perakaran yang banyak dan kuat. Penanaman tanaman perlindungan ini dapat juga diterapkan untuk perlindungan mataair, danau, waduk, tebing jurang, lahan gambut dan daerah resapan air.

C. Hutan rakyat yaitu hutan yang tumbuh atau dikembangkan pada lahan milik rakyat/adat/ulayat atau lahan-lahan lainnya yang berada di luar kawasan hutan. (Departemen Kehutanan, 1997: 230)

Wanatani (agroforestry) yaitu manajemen pemanfaatan lahan secara optimal dan lestari, dengan cara mengkombinasikan kegiatan kehutanan dan pertanian pada unit pengolahan sosial, ekonomi dan budaya masyarakat berperanserta (Departemen Kehutanan, 1997: 232). Arsyad (1989: 197) menerjemahkan agroforestry dengan istilah pertanian hutan. Bentuk usahatani yang dapat dikategorikan sebagai pertanian hutan meliputi: kebun 
pekarangan, talun kebun, perladangan, tumpangsari, rumput hutan, perikanan hutan dan pertanaman lorong.

D. Perkebunan yaitu lahan yang ditanamai berbagai jenis tanaman tahunan dan tanaman keras lainnya yang menghasilkan buah-buahan.

E. Pengendali adalah bangunan pengawetan tanah dan air berupa bendungan kecil dan berfungsi sebagai penampung air dan sedimen. Ada dua tipe dam pengendali, yaitu tipe kedap air dan tipe urugan tanah homogen (UTH). Tipe kedap air yaitu dam pengendali dengan badan bendungan yang terbuat dari konstruksi batu bata/beton sedangkan tipe urugan anah homogen. yaitu badan bendungnya terbuat dari konstruksi urugan tanah yang dipadatkan. (Departemen Kehutanan, 1997: 230).

F. Sumbat jurang (gully plug) adalah bangunan pengawet tanah dan air berupa bendungan kecil, dengan konstruksi terbuat dari urugan tanah dan gebalan rumput, batu bronjong atau kayu/bambu yang berfungsi untuk menahan sedimen yang berasal dari erosi parit. (Departemen Kehutanan, 1997: 230-231).

G. Bronjong batu adalah bangunan pengawet tanah berupa kawat bronjong yang diisi dengan batu atau beton yang dipasang pada tebing sungai terutama pada alur yang berbentuk kelokan. Bangunan ini berfungsi sebagai penahan tebing sungai dari daya gerus aliran air sungai.

H. Saluran pembuangan air adalah bangunan pengawet tanah berupa saluran air yang pada dinding dan dasar salurannya ditanami rumput yang merayap. Saluran ini berfungsi untuk mengalirkan aliran permukaan secara aman tanpa menimbulkan erosi. (Departemen Kehutanan, 1997: 267).

I. Saluran pengelak adalah suatu cara konservasi tanah dengan membuat semacam parit atau saluran memotong arah lereng dengan kemiringan yang kecil sehingga kecepatan air tidak lebih dari $0,5 \mathrm{~m} /$ detik. Saluran 
pengelak biasanya dibuat pada tanah yang berlereng panjang dan seragam yang permeabilitasnya rendah. (Arsyad, 1989: 121). Dalam Bahasa Inggris saluran pengelak disebut diversion ditch, diversion channels, atau diversion terrace

J. Teras bangku atau tangga dibuat dengan jalan memotong lereng dan meratakan tanah di bagian bawah sehingga terbentuk suatu deretan anak tangga atau bangku yang dipisahkan oleh talud. (Suripin, 2004: 118). Talud (riser) harus ditanami rumput-rumputan atau tanaman penutup lain agar terlindungi dari erosi percikan ataupun erosi permukaan, begitu pula pada bibir teras (lip) perlu diperkuat dengan tanaman penguat teras. Agar bidang olah cukup lebar dan agar tidak mudah longsor, teras bangku dibuat pada lahan kering untuk tanaman semusim dengan kemiringan kurang dari 40\%. (Departemen Kehutanan, 1997: 267).

K. Teras guludan adalah bentuk konservasi tanah dengan membuat guludan yaitu tumpukan tanah (galengan) yang dibuat memanjang memotong kemiringan lahan. Fungsi guludan ini adalah untuk menghambat aliran permukaan, menyimpan air di bagian atasnya dan untuk memotong panjang lereng. Tinggi tumpukan tanah berkisar antara $25-30 \mathrm{~cm}$ dengan lebar dasar 25-30cm. (Suripin, 2004: 116). Pada lahan yang berlereng curam atau lahan yang peka terhadap erosi dapat digunakan guludan bersaluran. Pada sistem guludan bersaluran, di sebelah atas guludan dibuat saluran memanjang mengikuti guludan.

Departemen Kehutanan RI melalui Direktorat Jendral Reboisasi dan Rehabilitasi Lahan (1998) menyebutkan bahwa pemilihan bentuk teras selain didasarkan pada kemiringan lereng juga harus mempertimbangkan kedalaman tanah, yaitu pembuatan teras dapat diterapkan pada lahan yang memiliki kedalaman tanah minimal $>30 \mathrm{~cm}$. Pelaksanaan rehabilitasi lahan dan konservasi tanah untuk masing-masing kawasan harus 
mampertimbangkan persyaratan karakteristik fisik pada masing-masing satuan lahan yang berupa kemiringan lereng dan kedalaman tanah.

Sistem Informasi Geografis adalah sistem komputer yang digunakan untuk mengumpulkan, memeriksa, dan menganalisa dan menyebarkan informasi-informasi yang berhubungan dengan permukaan bumi. (Damers dalam Prahasta, 2002: 55). Menurut ESRI (1990) dalam Prahasta (2002: 55), Sistem Informasi Geografis didefinisikan sebagai kumpulan yang terorganisir dari perangkat keras komputer, perangkat lunak, data geografi dan personil yang dirancang secara efisien untuk memperoleh, menyimpan, mengupdate, memanipulasi, menganalisis dan menampilkan semua bentuk informasi yang bereferensi geografi.

Secara umum, terdapat dua jenis fungsi analisis di dalam SIG yaitu fungsi analisis spasial dan fungsi analisis atribut, yang termasuk ke dalam fungsi analisis spasial diantaranya adalah overlay dan buffering.

Overlay adalah salah satu dari fungsi analisis spasial yang menghasilkan data spasial baru dari minimal dua data spasial yang menjadi masukannya. Sebagai contoh, bila untuk menghasilkan wilayah-wilayah yang sesuai untuk budidaya tanaman tertentu (misalnya padi) diperlukan data ketinggian permukaan bumi, kadar air tanah, dan jenis tanah, maka fungsi analisis spasial overlay akan dikenakan terhadap ketiga data spasial (dan atribut) tersebut.

Buffering adalah salah satu dari fungsi analisis spasial yang menghasilkan data spasial baru yang berbentuk poligon atau zone dengan jarak tertentu dari data spasial yang menjadi masukannya. Data spasial titik akan menghasilkan data spasial baru yang berupa lingkaran-lingkaran yang mengelilingi titik-titik pusatnya. Untuk data spasial garis akan menghasilkan poligon yang melingkupi garis-garis. Demikian pula untuk data spasial 
poligon, akan menghasilkan data spasial baru yang berupa poligon-poligon yang lebih besar dan konsentris.(Prahasta, 2002: 74)

Sistem Informasi Geografis dapat diaplikasikan untuk berbagai bidang kajian keilmuan. Prahasta (2002: 4) menyatakan bahwa :

"Banyak sekali aplikasi-aplikasi yang dapat ditangani oleh Sistem Informasi Geografis, salah satunya adalah aplikasi di bidang sumberdaya alam yang meliputi (inventarisasi, manajemen, dan kesesuaian lahan, untuk pertanian, perkebunan, kehutanan, perencanaan tata guna lahan, analisis daerah rawan bencana alam, dan sebagainya)".

Prahasta (2002 : 6-8) menyatakan bahwa banyak alasan mengapa dalam berbagai kajian keilmuan sering memanfatkan SIG, diantaranya adalah :

1) SIG dapat menurunkan data-data secara otomatis tanpa keharusan untuk melakukan interpretasi secara manual (terutama interpretasi secara visual dengan menggunakan mata manusia). Dengan demikian, SIG dengan mudah dapat menghasilkan peta-peta tematik yang merupakan peta turunan dari peta-peta yang lain dengan hanya memanipulasi atribut-atributnya.

2) SIG sangat membantu pekerjaan-pekerjaan yang erat kaitannya dengan bidang-bidang spasial dan geo-informasi. Dengan demikian SIG juga dapat digunakan sebagai alat komunikasi dan integrasi antar disiplin ilmu (terutama disiplin ilmu yang memerlukan informasi-informasi mengenai bumi atau geosciences)

Berdasarkan kenampakan peta penggunaan lahan kota Padang keluaran Bappeda Tahun 1997, maka penggunaan lahan pada daerah penelitian tergolong bervariasi. Hutan terdapat di Kecamatan Koto Tangah,Kecamatan Pauh. Kebun campuran tersebar di Kecamatan Kuranji dan Kecamatan Pauh. Ladang terdapat di Kecamatan Kuranji. Permukiman terdapat diseluruh yang dialiri oleh DAS Batang Kuranji Kota Padang. Persawahan tersebar pada 
Kecamatan Kota Tangah, Kecamatan Nanggalo, Kecamatan Kuranji dan Kecamatan Pauh. Semak tersebar di Kecamatan Kota Tangah dan,Kecamatan Kuranji. Luas Persebaran masing-masing penggunaan lahan di DAS Batang Kuranji yang dihitung dengan pengolahan data sekunder mengunakan Software Arcview dapat dilihat pada Tabel IV.5 berikut ini :

Tabel IV.5 Luas Persebaran penggunaan lahan DAS Batang Kuranji

\begin{tabular}{|c|c|c|c|}
\hline No & $\begin{array}{c}\text { Penggunaan } \\
\text { lahan }\end{array}$ & $\begin{array}{c}\text { Luas }( \\
\left.\mathbf{K m}^{\mathbf{2}}\right)\end{array}$ & $\begin{array}{c}\text { Persentase } \\
\mathbf{( \% )}\end{array}$ \\
\hline 1 & Hutan & 84,15 & 46,48 \\
\hline 2 & $\begin{array}{c}\text { Kebun } \\
\text { Campuran }\end{array}$ & 50,25 & 27,76 \\
\hline 3 & Ladang & 1,03 & 0,56 \\
\hline 4 & Permukiman & 11,28 & 6,23 \\
\hline 5 & Sawah & 29,39 & 16,23 \\
\hline 6 & $\begin{array}{c}\text { Semak } \\
\text { Belukar }\end{array}$ & 4,90 & 2,70 \\
\hline & Jumlah & $\mathbf{1 8 1}$ & $\mathbf{1 0 0}$ \\
\hline
\end{tabular}

Sumber: Peta penggunaan lahan DAS Kuranji Tahun 1997 Skala 1 : 50.000 Arahan Reklamasi Lahan Daerah Aliran Sungai Batang Kuranji.

Sesuai dengan pengunaan lahan daerah aliran sungai Batang Kuranji yang terdapat pada daerah penelitian, maka untuk arahan Reklamasi lahan di lakukan pada daerah aliran sungai dilakukan dengan cara Konservasi tanah, metode konservasi tanah dapat dikelompokkan menjadi tiga golongan utama, 
yaitu : (1) secara agronomis atau vegetatif, (2) secara mekanik dan (3) secara kimia. (Suripin, 2004: 101). Konservasi tanah secara vegetatif adalah penggunaan tanaman atau tumbuhan dan sisa tanaman dengan cara sedemikian rupa sehingga dapat mengurangi laju erosi dengan cara mengurangi daya rusak hujan yang jatuh dan jumlah daya rusak aliran permukaan. Konservasi tanah secara mekanik adalah konsevasi yang berkonsentrasi pada penyiapan tanah supaya dapat ditumbuhi vegetasi yang lebat, dan cara mamanipulasi topografi mikro untuk mengendalikan aliran air dan angin (Suripin, 2004 dalam Irma s,2014).

Dari hasil penelitian dilapangan terdapat dua Tingkatan Degradasi Fisik lahan pada Daerah Aliran Sungai (DAS) Batang Kuranji yaitu 1) Tingkat Degradasi Fisik Lahan Sedang dan, 2) Tingkat Degradasi Fisik Lahan Tinggi. Reklamsi lahan yang dilakukan pada Tingkat Degradasi Sedang dapat dilakukan dengan cara konservasi tanah baik itu dengan metode agronomis atau vegetatif, mekanik maupun kimia, namun yang menjadi pertimbangan disini adalah kemiringan lereng, satuan lahan, kedalaman solum tanah dan penggunaan lahan.

Arahan fungsi pemanfaatan lahan juga dapat diartikan sebagai upaya untuk menata pemanfaatan lahan pada suatu kawasan sesuai dengan kemampuannya. Dalam hal ini tujuan dari arahan fungsi pemanfaatan lahan adalah untuk mencapai keseimbangan antara kemampuan lahan dengan jenis pemanfaatan dan teknologi yang digunakan sebagai upaya untuk melindungi kelangsungan fungsi dan manfaat sumberdaya alam di suatu DAS. Artinya apabila penggunaan lahan pada masing-masing kawasan tidak sesuai dengan fungsi utamanya maka perlu dilakukan tindakan arahan fungsi pemanfaatan lahan dengan menerapkan tindakan rehabilitasi lahan dan konservasi tanah secara vegetatif dan mekanik yang bertujuan untuk mengembalikan dan menjaga fungsi utama kawasannya. 
Utomo (1994) memberikan definisi konservasi dan rehabilitasi tanah sebagai berikut :

Konservasi tanah adalah menggunakan tanah sesuai dengan daya guna dan kemampuan kemudian jika kita sudah memanfaatkannya kita harus memelihara/mempertahankan produktifitasnya dengan jalan memperlakukan dengan syarat yang diperlukan. Dan jika menghadapi tanah yang telah telanjur rusak, kita bertugas untuk memperbaiki produktifitasnya. Kegiatan yang terakhir ini juga dikenal dengan istilah "reklamasi tanah" atau rehabilitasi tanah.

Konservasi tanah tidak berarti penundaan pemanfaatan tanah, tetapi menyesuaikan macam penggunaannya dengan sifat-sifat atau kemampuan tanah dan memberikan perlakuan dengan syarat-syarat yang diperlukan.

Secara garis besar metode konservasi tanah dapat dikelompokkan menjadi tiga golongan utama, yaitu : (1) secara agronomis atau vegetatif, (2) secara mekanik dan (3) secara kimia (Suripin, 2004 ).

1. Konservasi tanah secara vegetatif adalah: penggunaan tanaman atau tumbuhan dan sisa tanaman dengan cara sedemikian rupa sehingga dapat mengurangi laju erosi dengan cara mengurangi daya rusak hujan yang jatuh dan jumlah daya rusak aliran permukaan.

2. Konservasi tanah secara mekanik adalah : konsevasi yang berkonsentrasi pada penyiapan tanah supaya dapat ditumbuhi vegetasi yang lebat, dan cara memanipulasi topografi mikro untuk mengendalikan aliran air dan angin (Suripin, 2004 ).

3. Konservasi tanah secara kimia.

Arahan fungsi pemanfaatan lahan merupakan bagian dari Pola Rehabilitasi Lahan dan Konservasi Tanah yang biasanya menggunakan 
Daerah Aliran Sungai (DAS) sebagai unit perencanaan sekaligus sebagai unit wilayah kerja kegiatan rehabilitasi lahan dan konservasi tanah.

\section{PENUTUP (Times new romans 12 bold)}

Berdasarkan hasil penelitian tersebut penulis mengambil kesimpulan daerah penelitian yaitu Daerah Aliran Sungai (DAS) Batang Kuranji perlu dilakukan Reklamasi lahan karena daerah ini mengalami penurunan kwalitas tanah. Untuk pencagahan terjadinyak kerusakan lahan yang berkelanjutan, adapun cara yang dilakukan untuk reklamasi lahan tersebut dengan cara konservasi tanah baik itu cara (1) secara agronomis atau vegetatif, (2) secara mekanik dan (3) secara kimia.

Berdasarkan kesimpulan di atas maka disarankan:

1. Rekomendasi untuk peneliti yang melekukan penelitian di masa yang akan datang hendaknya memperhatikan Tingkat Degradasi lahan dan Kondisi fisik lahan pada setiap pengguaan lahan agar dapat melakukan Reklamasi sesuai dengan fungsi dari masing- masing kawasan.

2. Pemerintah Kota Padang disarankan untuk dapat mengatur penggunaan lahan sesuai dengan fungsinya.

3. Perkembangan pemukiman baru sebaiknya dilakukan tidak pada Daerah Aliran Sungai untuk menghindari terjadinya kerusakan lahan atau degradasi lahan. 


\section{DAFTAR PUSTAKA}

Arsyad, 1989. Hidrologi Dan Pengelolaan Daerah Aliran Sungai. Gadjah Mada university press. Yogyakarta

Hanafiah,Kemas Ali, ( 2012) Dasar-dasar Ilmu Tanah Rajawali Press.Jakarta Njurumana (2013) Kajian Degradasi Lahan Pada Daerah Aliran Sungai Kambaniru, Kabupaten Sumba Timur. Balai Penelitian kahutanan Kupang. http://ejournal.unud.ac.id/

Sirang,K, dan Kadir (2013) Reklamsi Kajian Rencana Teknik Rehabilitasi Hutan dan Lahan di DAS Batulicin Provinsi Kalimantan Selatan, Program Studi Manajemen Hutan, Fakultas Kahutanan Universitas Lambung Mangkurat. http://ejournal.unud.ac.id/.

Soermartono, O, ( 1990 ) Analisis Menganai Dampak Lingkungan, Gajah mada University Pres.

Suhardiman. 2012. Zonasi Tingkat Kerawanan Banjir Dengan Sistem Informasi Geografis (SIG) Pada Sub DAS Walanae Hilir . skripsi. Makasar : universitas hasanuddin

Sunarto dan jamulya (1995) Evaluasi Sumber Daya Lahan : metodologi dan terapan untuk ESL. UGM. Yokyakarta.

Sulistio,H, (2013) Permodelan Konservasi DAS Karang Anyar,Jurusan Teknik Sipil Universitas 17 Agustus Samarinda 1945 http://ejournal.unud.ac.id/

Suprato,(2013) Tinjauan Reklamasi lahan Bekas Tambang dan Aspek Konservasi bahan Galian, kelompok progam penelitian Konsevasipusat sumber daya geologi, http://ejournal.unud.ac.id/

Suarna. I.W. 2010 Studi Perubahan Penggunaan Lahan Di DAS Bandung http://ejournal.unud.ac.id/

Suprayogo,D, dkk (2013) Degradasi Sifat Fisik Tanah Sebagai Akibat Alih

Guna Lahan Hutan menjadi Sistem Kopi Monokultur: kajian perunahan makropopositas tanah, ICRAF SE Asia,PO Box 161, Bogor 16001 http://ejournal.unud.ac.id/

Suripin (2004) Evaluasi Kekritisan lahan Daerah Aliran Sungai (DAS) dan Mendesaknya Langkah-langkah Konsevasi Air, program Studi Teknik Lingkungan FT Undip, http://ejournal.unud.ac.id/

Irma S,Ade (2014) tesis Tingkat Degradasi fisik lahan Daerah Aliran Sungai (DAS) Batang Kuranji Kota Padang 